\title{
Stakeholder Identification in Vietnamese Private Higher Education Institutions
}

\author{
Vinh Q. Bui \\ School of Communication, International studies and Languages, University of South Australia, Adelaide, Australia \\ Email: buiqy003@mymail.unisa.edu.au
}

\begin{abstract}
The purpose of this study is to provide empirical insights into stakeholder identification (SI) in specific context of Vietnamese private higher education institutions (VPHEIs). Existing literature points to the pervasive relationship-centric paradigm of stakeholder identification that is applicable to higher education institutions (HEIs). This paper argues that VPHEIs need to effectively manage relationships with stakeholders who influence challenging issues that face the institutions. This paper addresses the question: how do VPHEIs identify stakeholders? Data from key informant interviews and participant observations were triangulated to compare and contrast the findings. The key finding is that VPHEIs management identify key stakeholders differently. The data indicated that interpersonal relationships influence VPHEIs management approach to stakeholder identification rather than the understanding and application of stakeholder theory. ${ }^{1}$
\end{abstract}

Index Terms - Higher Education, Stakeholder identification, private university, Vietnam.

\section{INTRODUCTION}

The stakeholder approach to strategic management has been discussed in literature over 30 years. A consensus is that organizations need to effectively identify and manage relationships with key stakeholders to obtain organizational success [1], [2]. Scholars studying HEIs also argue that the ability to manage stakeholder relationships significantly influences institutional success [3]-[5]. This study investigate the practice of SI in VPHEIs to verify if the current SI paradigms found in the Western literature is applicable to the specific context of a transitional developing country. This paper contributes empirical insights into an area of limited research regarding the SI in HEIs, especially in non-Western contexts.

In Vietnam, the management of HEIs has undergone substantial reforms since the implementation of the Government's 'renovation policy', or "Doimoi" in Vietnamese from the Government [6]. These reforms include the emergence of private sector that plays an important role in meeting the unmet demand for tertiary education [7], [8]. Currently, the whole HE systems only provide places for around $10 \%$ of the university age population [9]. In 2005, the Vietnamese government enacted the Higher Education Reform Agenda (HERA).

Manuscript received December 2, 2015; revised March 30, 2016.
One of HERA's ambitious objectives is to increase student enrolment to reach the gross enrolment rate about $45 \%$ of the total university age population by 2020 [6]. However, the public sector cannot provide educational opportunities for all potential students who want a tertiary degree [9]. Therefore, another HERA's objective is that the private sector has to account for up to $40 \%$ of this gross enrolment rate. To do so, VPHEIs have to overcome significant challenging issues that threaten their existence. First, VPHEIs face difficulties in optimizing student recruitment since the first choice for students entering HE is nearly always a public institution [6]. Second, ensuring quality of education in VPHEIs is problematic. One reason is the lack of autonomous operations and financial resources that restrict VPHEIs in recruiting qualified academic staff [10]. The other reason is the framed curriculum imposed by the Ministry of Education and Training (MOET) that stresses on quantity rather on the quality of knowledge [11]. A third crucial issues is low graduate employability of VPHEIs due to employer preference for graduates from public universities and the loose connections between universities and the employment market [12]. In this context, it is argued that if VPHEIs effectively identify and manage relationships with key stakeholders who influence these challenging issues, they might obtain competitiveness over the public universities to reach the HERA's target.

\section{STAKEHOLDER IDENTIFICATION IN HIGHER EDUCATION INSTITUTIONS}

The competitive, complex and dynamic environment necessitates an HEI to effectively manage relationships with various stakeholders [13]. Stakeholders are defined as individuals and/or groups on which the organization is dependent on for its continual survival [14]. The nature of stakeholder relationships varies across organizations, industries and contexts [14]. However, a consensus is that stakeholders are important elements in the constitutions of the organization and that attention must be paid to their interests [14]-[16]. Complex organizations, such as universities, that recognize the stakeholder network in which they are inextricably embedded and work to engage with relevant stakeholders are able to obtain competitiveness [14], [5]. Although universities are different from business organizations, stakeholder approach may be applied because an university, as any 
organization, is a social system with a need for legitimacy and social acceptance [17].

Stakeholder identification have shifted from organization-centric approaches [18], [19] to more stakeholder-centric approaches [20], [21], and recently to relationship-centric approaches [22], [14], [23]-[25]. The organization-centric and stakeholder-centric place the focal organizations in the centre of dyadic linkages with surrounding stakeholders whereas stakeholder relationships are dynamic and complex. Thus, these approaches are not relevant in heterogeneous and critical environment [26], [23], such as one of HEIs. The relationship-centric approach emphasize the interrelated network of relationships that naturally exist among stakeholders in which the organizations are only partly control the relationship processes [24], [23]. This approach highlights the notion of stakeholder reciprocity, which have been neglected in previous stakeholder research [27]. This notion emphasizes that stakeholders and organizations not only have abilities to affect each other, but also have responsibilities to each other for mutual interests. For example, the issue-network approach [23] focus on issues that force stakeholders relating to these issues to collaborate with each other and with the organization to interact for resolving the issues. This study adopted this issue-network approach to investigate the practice of stakeholder identification in relations with challenging issues facing VPHEIs.

Different frameworks of SI are proposed by scholars studying HEIs stakeholders. For example, many efforts of HEI's stakeholder identification rely on Mitchell et al.'s [20] stakeholder salience paradigm. The problem is that the different theoretical approaches adopted by researchers lead to inconsistencies in stakeholder identification [5]. Nevetheless, HEIs are required to clearly indentify key stakeholders, to address their needs and manage respective stakeholder relationships to be connected to wider communities [13]. The relative importance of different stakeholders depending upon three factors that have direct, partial or indirect influence on student recruitment and satisfaction, on university's policies and strategies, and on university's income [28]. Therefore, an applicable process of SI in HEIs includes: 1) identifying of key stakeholders and their importance to the institutions; 2) determining expectations of these stakeholders and 3) establishing relationships with these stakeholders to satisfy their expectations [29]. However, stakeholders are not the same for all HEIs [5]. Furthermore, no SR paradigm can fix to all contexts [30]. Little attention has been paid to stakeholder identification in the centralised economies [31]. Thus, further investigation is needed to provide empirical insights to SI in such contexts.

In the socialist countries, such as Vietnam, universities play solely marginal roles and certainly need to accept certain changes [32]. These crucial changes include the improvement of curricula to the need of stakeholders and the successful communication with all relevant stakeholders. In hard conditions of the transition of developing economies, universities have to understand the role of their stakeholder, identify their primary stakeholder and use appropriate strategies to maintain relationships with these stakeholders [32].

In Vietnam, as a centralised economy, the notion of privatization in HE is at odds with socialist ideology [8] and cultural beliefs place higher value on public HEIs [6]. Such ideology and beliefs create difficulties for VPHEIs to compete against the public universities. Especially, the regulatory system for VPHEIs is insufficient and inappropriate due to the old ways of thinking of the policy makers [33]. Consequently, the pervasive prejudice of VPHEIs as second rate and low quality HE service provider influence their ability to compete against public universities [34]. Thus, VPHEIs need to incorporate resources from multiple stakeholders to enhance their competitiveness. However, studies on stakeholder identification in VPHEIs are scarce.

This study argued that a VPHEI, as a complex organization, needs to effectively identify key stakeholders on whom it is dependent for survival to obtain its competitiveness. The hypothesises are: 1) a clear stakeholder network relating to the challenging issues of VPHEIs needs to be identified and 2) VPHEIs, with limited resources, need to focus on its most strategic stakeholders who possesses values and resources to resolve the challenging issues facing the institutions. This study examined the practice of stakeholder identification in VPHEIs, focused on what types of values and shared goals to generate what degree of importance of each stakeholder to VPHEIs. The key research question is: How do VPHEIs manage relationships with stakeholders?

\section{RESEARCH METHODS}

This study was implemented in Ho Chi Minh City, Vietnam where the majority of VPHEIs are located. A qualitative approach was used to answer "how" question [35], [36]. This approach empowered VPHEIs management to share their experiences and perceptions and allowed the researcher's direct participation to discover the socio-cultural aspects of stakeholder identification, rather than to rely on philosophical assumptions based on the literature.

Two data collection methods, in-depth semi-structured interviews and participant observations were employed. Interviews were conducted with key informants who have direct experience with stakeholder identification, namely the decision-makers such as principals or presidents, Public Relations or Communication managers in VPHEIs. The high school principals, the MOET officers, business employers and the media reporters were also interviewed.

The participants were recruited based on the short list of VPHEIs listed in the websites of the Ministry of Education and Training (www.moet.gov.vn) and the nonpublic University Associations in Vietnam (www.giaoduc.net.vn). Using contact information (email and telephone numbers provided in the websites), invitation emails were sent to the targeted informants.

The semi-structured interviews were followed the responsive interviewing model [37] which includes main questions, probes and follow-up questions. The questions 
were modified in accordance with the actual responses of the informants. Participants were asked about the practice of RM in their universities. Twenty-three interviews took place from 29 November 2013 to 27 January 2014 in Vietnam at the venues agreed with the participants. Each interview lasted about 45-60 minutes and is fully recorded then transcribed and translated into English before analysis.

The interviews in the particular context of Vietnam with a centralized communist national government, where free speech is restricted due to the rigid information regulating system [38], might not reveal all the covert insights of the participants' thoughts and perceptions. Thus, to allow for this, observations, as a form of data collection to construct the meaning through the witnessing of daily incidents and events within the natural context of studied subjects [39], provide a richer understanding in this context. A direct, non-participant method of observation was used to better understand stakeholder identifications in VPHEIs without relying on prior conceptualization and to capture insights that participants would be unwilling to reveal in interviews. During 40 hours of observations, I took a part in daily activities, interactions and events of the studied subjects, the stakeholders of VPHEIs, by attending management meetings, events and activities at the VPHEIs. During the meetings or events, I observed how various stakeholders, such as lecturers, staff, school leavers and parents, communicate and interact to capture relevant insights into the levels of important of each stakeholder group in VPHEIs. Data from observations allowed triangulation with data from interviews to enhance the reliability of this study.

\section{PERSONAL INFLUENCE ON STAKEHOLDER IDENTIFICATION}

All of the data shows that the practice of stakeholder identification in VPHEIs is significantly influenced by interpersonal relationships. The institutional approach to SI is influenced by the personal perspective of the leaderships. Interpersonal relationships between managers of VPHEIs and individual stakeholders are crucial in the implementation of SI.

\section{A. Personal Perspective of the Leaders Influence Institutional Approach to Stakeholder Identification}

A key finding is that VPHEIs management is aware of a wider range of stakeholders and understand the expectations of all stakeholders to the institutions. However, they do not manage relationships with all identifiable stakeholders and only focus on certain stakeholders in relations to the issues that face the institutions. The interviews with the management staff of three different VPHEIs indicated that the perspective of the leadership toward the issues that face their institutions influence the practice of SI differently among the VPHEIs. For example, the leaders of one university the focus on quality of education and in its management identify and manage relationships with stakeholders who have capability to influence quality of education, such as academic and business partners. In contrast, the leaders of another university focus on student recruitment, thus its management prioritize relationships with stakeholders who are believed to influence student recruitment. This finding support the argument of the issue-network approach to SI that managers likely to determine relationships with relevant stakeholders of the specific issue [24]. This approach to SI emphasizes that interactions with stakeholders are more personal in the issue-network relationships [23]. The observations also indicates a high personal involvement of the managers in the interpersonal interactions with individual stakeholders. That is, VPHEIs manage interpersonal relationships with individual stakeholders rather than simply categorize and manage relationships with groups of stakeholder. Therefore, this paper suggests that an issue-network approach might be applicable for SI in VPHEIs.

There is a clear evidence that the VPHEIs focus on relationships with certain stakeholders while neglect or ignore the others. All of the data indicated that student recruitment is a key concern that influences the institutions focus on relationships with stakeholders who have ability to directly influence student recruitment, such as feeder high school management, potential students and parents. However, other critical stakeholders, such as current students and alumni who also influence student recruitment are frequently neglected or ignored by the respondents. For example, most of interviewers mentioned potential students and parent as key "customers" or "payer" first while listing who matters to the institutions. However, all of the interviewers only mentioned to alumni as stakeholders when asked. This finding support previous literature that HEIs are still unable to identify all key stakeholders and effectively manage stakeholder relationships [5]. Scholars studying stakeholders in HEIs state that a university needs to employ internal actors to proactively leverage the opportunities offered by various stakeholders [29]. This study also suggests that a comprehensive SI framework that balances relationships with all relevant stakeholders is needed for VPHEIs. Using interpersonal relationships, VPHEIs management should expand a wider network of stakeholder relationships. Such networks should include the currently ignored or neglected stakeholders including current students, alumni, businesses, academic partners, the MOET and other socio-political stakeholders such as the media, local communities and authorities.

\section{B. Interpersonal Relationships are Crucial in Forming and Nurturing Stakeholder Relationships}

The data also indicate that stakeholder relationships are formed and developed based on pre-existing interpersonal relationships. For example, a VPHEI's Principal emphasized that, "pre-existing interpersonal relationships are very important in relationships formation". The participants discussed the cultural factors of Vietnam such as the Confucius ideology, the social connections among individuals such as family ties and friendships influence stakeholder relationships in VPHEIs. For example, one Communication Manager of a VPHEIs emphasized that: "cultural factors that respect the 
diploma, which originates from Confucian ideology that influence the building of image and also the public's trust and communications activities." Consequently, Word of Mouth (WOM) influence generated from interpersonal interactions and communication significantly affects SI in VPHEIs. The interviewees believed that the WOM influence the formation and management of stakeholder relationship more vigorously than any other formal communication tools. For example, a President of a University said that, "Vietnam is a country where it seems to be that word of mouth is much, much more important than glossy brochures." This finding supports scholarship of relationship management in Asian cultures that trust-based relationships between an organization and its stakeholders are established and enhanced through WOM influence among individual stakeholders [40]-[43]. The current study argues that VPHEIs need to manage interpersonal relationships with individual stakeholders rather than simply categorize groups of stakeholders.

All of the data indicated that interpersonal relationships are important as a key relational strategy to implement other relational strategies. The exchange of favour in interpersonal relationships are used as precedents to three other key relational strategies namely, openness, sharing of tasks for stakeholder engagement and assurance by satisfying stakeholder expectations. For example, the interviewers indicated that their university employ the PR staff who have his/her own set of interpersonal relationships with the representatives of the authorities such as the MOET and with the media reporters. The observation showed that VPHEIs use interpersonal relationships to build relationships with business partners and with representatives of feeder high schools. The interviewed VPHEIs' management explained that they use gifts as "lubricant" for the interpersonal relationships. Clearly, the practice of giftgiving, as a rule of reciprocity for favour exchange, is important in nurturing stakeholder relationships in VPHEIs. The cultural practice of gift-giving (both monetary and non-monetary) and "envelope culture" are used as a key strategy to build and nurture such relationships. As a result, these stakeholders support VPHEIs as the returning of the owed favours. This finding is consistent with other studies of organizationstakeholder relationships in Confucian-influenced contexts in pointing to the exchange of favour (renqing) and keeping-face (mianzi) as key relational strategies [41], [40]. However, some interviewees mentioned the negative aspects of this practice such as the bribe and corruption. Such aspects might undermine and detort the nature of stakeholder relationships since stakeholders are involuntarily engaged into relationships for favour exchange and face protections. Such cultural practice also create negative perceptions of VPHEIs that use monetary favours as bribery to obtain favourable support from the

\footnotetext{
${ }^{1}$ As common practice in Vietnam, after the events, the reporters and/or representative of authorities and invited guests receive a "thank you" envelope with cash, from VND 500,000-1,000,000 VND (AUD 25-50) depending on the budget of the events.
}

MOET and authorities to operate without meeting standard requirements.

Interpersonal interactions and communication, such as dialogue and face-to-face meetings are used to nurture institution-stakeholder relationships. All data indicated that to compete with the prestigious Vietnamese public universities, VPHEIs need to demonstrate integrity, to engage with stakeholders and to ensure their capacity to satisfy stakeholder expectations. To do so, VPHEIs employ interpersonal interactions and communication to share information with stakeholders, to engage individual stakeholders in the institutional activities and to demonstrate that university offerings match stakeholder expectations. For example, a VPHEI use dialogue and face-to-face as an "open system" to create conditions for stakeholders to obtain and exchange information about the institution. The Communication Manager of this VPHEIs said in such interaction students and other stakeholders can "voice it if they have some issues". This finding supports scholarship in relationship management that all relationships have a personal dimension that is based on social networking and interactions with other individuals [44], [45]. It also consolidates a view within scholarship that relationships in Vietnam is understood as quan hẹ (or social connections) to improve interpersonal relationships [42]. Thus, this paper argues that interpersonal relationships might be used to justify the theoretical framework, such as the issue-network model, to the specific context of a collective culture in Vietnam.

\section{CONCLUSIONS}

The purpose of this study is to provide empirical insights of SI in VPHEIs to the theory of SI. Drawing on literature of SI, an applicable process of SI requires a clear identification of key stakeholders and their expectations to implement appropriate relational strategies to build and maintain stakeholder relationships. This study shows that in VPHEIs, interpersonal relationships influence SI rather than the understanding and application of SI theory. The practice of SI in VPHEIs is based on the interpersonal relationships both as precedents to form and as a key relational strategy to nurture stakeholder relationships. Therefore, this paper argues that VPHEIs management need to build knowledge and understanding of SI and use interpersonal relationships to build and develop stakeholder relationships based on the issue-network approach to the practice of SI.

Although this study suggest initial steps for SI in VPHEIs, some caution should be considered while applying these steps in practice. First, the research participants were limited in one city and in certain VPHEIs with visible success. Second, the results relied on the perceptions of individual participants. Thus, this study might not provide a generalization for the practice of SI in the whole higher education system of Vietnam. Further research need to focus on the process of SI in other less success VPHEIs and in wider contexts to have a deeper insight of SI in a transition economy. 


\section{REFERENCES}

[1] R. Freeman, Strategic Management: A Stakeholder Approach, Cambridge University Press, Cambridge, UK, 2010.

[2] J. Harrison, D. Bosse, and R. Phillips, "Managing for stakeholders, stakeholder utility functions, and competitive advantage," Strategic Management Journal, vol. 31, no. 1, pp. 58-74, July 2010.

[3] J. Kettunen, "The stakeholder map in higher education," International Journal of Learning and Teaching, vol. 1, no. 1, pp. 19-22, Dec. 2014.

[4] J. Kettunen, "Stakeholder relationships in higher education," Tertiary Education and Management, vol. 1, no. 2, pp. 1-10, Feb. 2015.

[5] H. Alves, E. W. Mainardes, and M. Raposo, "A relationship approach to higher education institution stakeholder management," Tertiary Education \& Management, vol. 16, no. 3, pp. 159-181, Aug. 2010.

[6] G. Harman, M. Hayden, and T. Phạm, "Higher education in vietnam: Reform, challenges and priorities," in Reforming higher Education in Vietnam, G. Harman, M. Hayden and T. Phạm (Editors), Springer, Dordrecht, New York, 2010, ch.1, pp. 1-13.

[7] L. Pham and G. Fry, "The emergence of private higher education in vietnam: challenges and opportunities," Educational Research for Policy and Practice, vol. 1, no. 1-2, pp. 127-141, Feb. 2002.

[8] A. Welch, "Ho chi minh meets the market: Public and private higher education in viet nam," International Education Journal: Comparative Perspectives, vol. 8, no. 3, pp. 35-56, Jan 2007.

[9] M. Hayden and Q. Lam, "Vietnam's higher education system," in Reforming Higher Education in Vietnam, G. Harman, M. Hayden and T. Phạm, Eds., Springer, Dordrecht, New York, 2010, ch. 2, pp. 14-29.

[10] D. Le, "The role of non-public institutions in higher education development of vietnam," Online Submission, PhD. Thesis, Hiroshima University, Japan, 2006, pp. 1-240.

[11] T. Pham, "An investigation of perceptions of vietnamese teachers and students toward cooperative learning," International Education Studies, vol. 4, no. 1, pp. 3-12, Feb. 2011.

[12] T. Tran, Graduate Employability in Vietnam: A Loose Relationship between Higher Education and Employment Market, Anchor Academic Publishing, Hamburg, Germany, 2014.

[13] B. Jongbloed, J. Enders, and C. Salerno, "Higher education and its communities: Interconnections, interdependencies and a research agenda," Higher Education, vol. 56, no. 3, pp. 303-324, April 2008.

[14] R. Freeman, J. Harrison, A. Wicks, B. Parmar and S. De Colle, Stakeholder Theory: The State of the Art, Cambridge University Press, Cambridge, UK, 2010.

[15] J. Harrison and A. Wicks, "Stakeholder theory, value, and firm performance," Business Ethics Quarterly, vol. 23, no. 1, pp. 97124, Jan 2013.

[16] R. Phillips, Stakeholder Theory, Edward Elgar Publishing, Cheltenham, 2011.

[17] M. Jorge, A. Hernández, and M. Cejas, "Stakeholder expectations in spanish public universities: An empirical study," International Journal of Humanities and Social Science, vol. 2, no. 10, pp. 1-13, May 2012.

[18] R. Freeman, Strategic Management: A Stakeholder Approach, Pitman, Boston, 1984.

[19] J. Grunig and T. Hunt, Managing Public Relations, Holt, Rinehart, Winston, New York, 1984.

[20] R. Mitchell, B. Agle, and D. Wood, "Toward a theory of stakeholder identification and salience: Defining the priniciple of who and what really counts," Academy of Management Review, vol. 22 , no. 4 , pp. 853-886, Oct. 1997.

[21] T. Rowley, "Moving beyond dyadic ties: A network theory of stakeholder influences," The Academy of Management Review, vol 22, no. 4, pp. 887-910, Oct. 1997.

[22] J. Bryson, "What to do when stakeholders matter: Stakeholder identification and analysis techniques," Public Management Review, vol. 6, no. 1, pp. 21-53, Jan. 2004.

[23] J. Roloff, "Learning from multi-stakeholder networks: Issuefocussed stakeholder management," Journal of Business Ethics, vol. 82, no. 1, pp. 233-250, Jan. 2008.

[24] J. Frooman, "The issue network: Reshaping the stakeholder model," Canadian Journal of Administrative Sciences/Revue
Canadienne des Sciences de l'Administration, vol. 27, no. 2, pp. 161-173, Feb. 2010.

[25] S. Sachs and E. Rühli, Stakeholders Matter: A New Paradigm for Strategy in Society, Cambridge University Press, Cambridge, New York, 2011.

[26] S. Sachs, H. Groth, and R. Schmitt, "The 'stakeholder VIEW' approach: An untapped opportunity to manage corporate performance and wealth," Strategic Change, vol. 19, no. 3-4, pp. 147-162, Feb. 2010

[27] Y. Fassin, "Stakeholder management, reciprocity and stakeholder responsibility," Journal of Business Ethics, vol. 109, no. 1, pp. 8396, June 2012.

[28] C. Chapleo and C. Simms, "Stakeholder analysis in higher education," Perspectives: Policy \& Practice in Higher Education, vol. 14, no. 1, pp. 12-20, Jan. 2010.

[29] E. Mainardes, M. Raposo, and H. Alves, "Universities need a market orientation to attract non-traditional stakeholders as new financing sources," Public Organization Review, vol. 14, no. 2, pp 159-171, Jan. 2014.

[30] A. B. Carroll and A. K. Buchholtz, Business \& Society: Ethics, Sustainability, and Stakeholder Management, South-Western Pub, 2011.

[31] O. Apostol and S. Näsi, "Institutional implications for stakeholder modelling: Looking at institutions in a centralised economy," Journal of Business Ethics, vol. 96, no. 1, pp. 33-38, Aug. 2010.

[32] L. Tetřevová and V. Sabolová, "University stakeholder management and university social sesponsibility," WSEAS Transactions on Advances in Engineering Education, vol. 7, no. 7 , pp. 224-233, July 2010.

[33] Q. Lam, "Non public education system in vietnam," in Proc. 1st Compared Education Conference, Hochiminh City University of Pedagogy, Vietnam, 2011, pp. 1-10.

[34] M. Hayden and V. Dao, "Private higher education in vietnam," in Reforming Higher Education in Vietnam, G. Harman, M. Hayden and T. Pham, Eds., Springer, London, 2010, ch.15, pp. 215-225.

[35] N. Denzin and Y. Lincoln, Collecting and Interpreting Qualitative Materials, SAGE, Thousand Oaks, CA, 2008.

[36] J. Maxwell, Qualitative Research Design: An Interactive Approach: An Interactive Approach, vol. 41, Sage, Thousand Oaks, CA, 2012.

[37] H. J. Rubin and I. Rubin, Qualitative Interviewing: The Art of Hearing Data, Sage Publications, Thousand Oaks, CA, 2005.

[38] S. Libby, "The art of censorship in vietnam," Journal of international Affairs, vol. 65, no. 1, pp. 209-218, Fall/Winter 2011

[39] R. K. Yin, Case Study Research: Design and Methods, Sage Publications, Thousand Oaks, CA, 2009.

[40] C. Hung, "Cultural influence on relationship cultivation strategies: Multinational companies in China," Journal of Communication Management, vol. 8, no. 3, pp. 264-281, Jan. 2004.

[41] Y. Huang, "A chinese perspective of intercultural organizationpublic relationship," Intercultural Communication Studies, vol. 12 no. 4, pp. 151-176, Dec. 2003.

[42] Q. H. Vuong and T. D. Tran, "The cultural dimensions of the vietnamese private entrepreneurship," ICFAI University Journal of Entrepreneurship, vol. 4, no. 3-4, pp. 54-78, Nov. 2009.

[43] T. Nguyen and J. Rose, "Building trust-evidence from vietnamese entrepreneurs," Journal of Business Venturing, vol. 24, no. 2, pp. 165-182, Jan. 2009.

[44] T. Falconi, C. White, A. Lorenzon, and K. Johnson, "Personal influence model," in How Big Is Public Relations (and Why Does It Matter), Institute for Public Relations, Mar 2009.

[45] J. Ledingham, "Relationship management: A general theory of public relations," in Public Relation Theory II, C. H. Botan and V. Hazleton, Eds., Lawrence Erlbaum Associates, London, 2006, ch. 18 , pp. $465-483$.

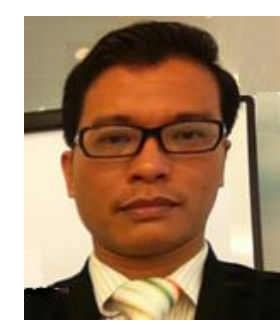

Vinh Q. Bui is an HDR student in the School of Communication, International Studies and Language, University of South Australia. He has 18 years of experience as a senior marketing managers. He is a former lecturer in Marketing and Public Relations in Ho Chi Minh City University of Technology (HUTECH). His current field of study includes communication and stakeholder identification. 
Mr. Bui is a member of Vietnamese Marketing Institution (VMI) and contributed to many consultant projects of VMI relating to marketing, Public Relations and Organization re-structure. 